\title{
Numerical Simulation of The Influence of Steep Coal Seam Mining to
}

\section{Roof Fault Activation}

\author{
Mingdong Zhao ${ }^{\mathrm{a}^{*}}$, Zilong Guan ${ }^{\mathrm{b}}$, Donglin Dong ${ }^{\mathrm{c}}$ \\ College of Geoscience and Surveying Engineering, China University of Mining and \\ Technology(Beijing), Beijing 100083, China \\ a zhaomingdong89@126.com, b1085568238@qq.com, c $302688299 @ q q . c o m$
}

Key words: Overturned stratum, Steep seam, Fault activation, FLAC3D, Linear regression

\begin{abstract}
The formation of a certain mine is the overturned stratum. The roof of coal seam is the limestone aquifer, which is cut by the normal fault. The deep mining of steep inclined coal seam is easy to cause the activation of fault and conduct limestone aquifer, resulting in water inrush accident. Facing the increasing of mining depth, this paper studies the effect of deep mining on fault activation in steep coal seam with FLAC ${ }^{3 \mathrm{D}}$ numerical simulation and linear regression method and summarizes the relationship between mining depth of steeply inclined coal seam and the degree of activation of roof fault. It has important engineering significance in predicting and controlling the fault water inrush in the study area.
\end{abstract}

\section{Introduction}

The hydrogeological conditions of the coal mine is very complex in China, a large proportion of water disasters in coal mine are caused by fault activation, which conduct the aquifer near the coal seam [1-5]. Therefore, the study of fault activation law in the process of coal mining is very important to the safety production in coal mine.

In recent years, many researchers have did a lot of research on the effect of fault in the process of coal mining. Liu et al.[6]fixed a design method of fault waterproof pillar, and classifiedthe waterproof coal pillar in waterproof function. Meng et al.[7] revealed the influence of the normal fault to the physical and mechanical properties of coal and the pressure distribution. Peng et al.[8] Used Mohr-Coulomb criteria to calculate the water inrush type of fault dip angle. Jiang et al.[9] did a lot of research of the time and space change law of normal stress and shear stress on the fault contact surface and the movement rule of the both sides of the fault. Chen et al.[10] used the numerical simulation method to study the stress distribution and deformation characteristics of the overlying strata in the heading side of the major fault zone.

The study of the influence of steep coal seam mining to roof fault activation is very less in domestic and overseas at present. This article uses the methods of FLAC3d numerical simulation and linear regression to study the influence of steep coal seam mining to roof fault activation.

\section{The establishment of the model in the study area}

Under the action of nappe structure, the strata was overturned in the study arear, and the dip angle of the primary mineable coal bed is about $75^{\circ}$, the thickness of the primary mineable coal bed is about $5 \mathrm{~m}$. The roof and floor of the primary mineable coal bed are mudstone and sandy mudstone. A normal fault located in the roof of the primary mineable coal bed, and cuts the aquifer 
in limestone. The distance of the normal fault and the primary mineable coal bed is about $200 \mathrm{~m}$. The gap between the fault is $9 \mathrm{~m}$, and the dip angle of the fault is $65^{\circ}$. According to the geological section map in the exploration line and the comprehensive stratigraphic columns in this study arear, the FLAC ${ }^{3 \mathrm{~d}}$ mechanical model was established, as shown in Fig.1. The size of the numerical model in group A (length $\times$ width $\times$ height) is set to $600 \times 400 \times 750$ m,there are 201560 units and 233751 nodes in this mechanical model.

Coal and rock in model are represented using Mohr-Coulomb plasticity model. The shearyield of zones complies with the Mohr-Coulombcriterion, as shown inEq. 1.

$$
f_{s}=\sigma_{1}-\sigma_{3} \frac{1+\sin \varphi}{1-\sin \varphi}-2 c \sqrt{\frac{1+\sin \varphi}{1-\sin \varphi}}
$$

In the formula: $\sigma_{1}$ is the maximum principal stress (MPa); $\sigma_{3}$ is the minimum principal stress $(\mathrm{MPa}) ; \varphi$ is the internal friction angle $\left(^{\circ}\right) ; c$ is the cohesive force (MPa). When $f_{s}>0$, shear failure will happen. Tensile failure of rock mass can be judged according to tensile criteria, when $\sigma_{3} \geq \sigma_{1}$, tensile failure will happen.

Horizontal direction constraints was imposed around the perimeterof the model, and the bottom boundary of the model was fixed, the upper boundary of the model was free. The load was imposed on the upper boundary of this model, which was equal to the weight of the overlying strata, 3.58MPa. In the numerical simulation, stress of primary rock was not considered, we only consider the stress caused by gravity ofthe strata. According to the rock mechanics test datain the study arear, the physical and mechanical parameters of rocks were obtained, as shown inTable 1.

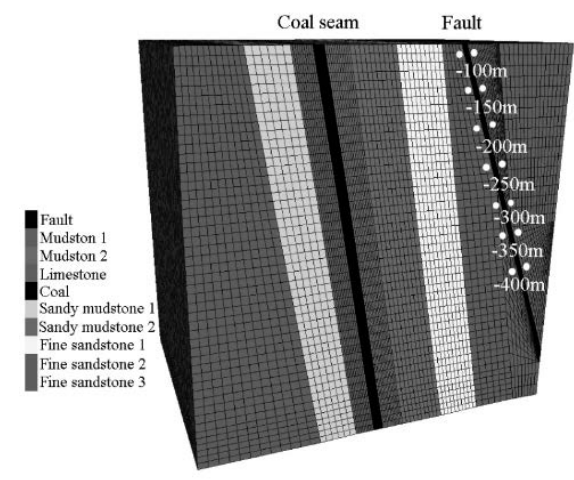

Fig.1 Geometric model of coal seam mining

Table 1 Physical mechanical parameters of coal or rocks

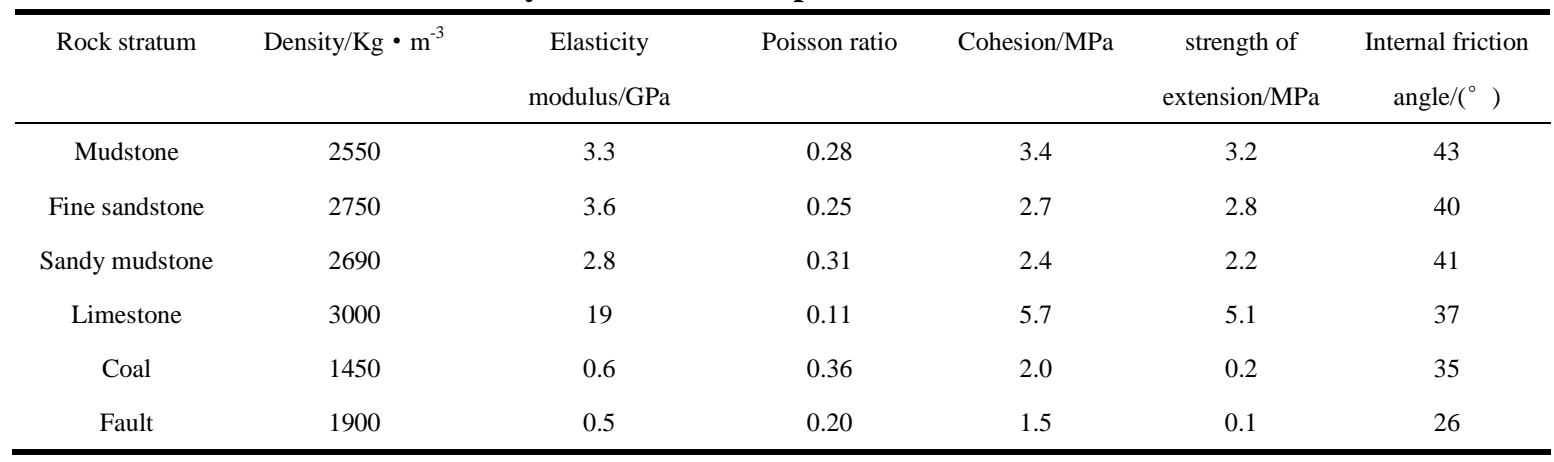

\section{Modeling scheme}

The mining method of this steep coal seam in the study arear is from top to bottom horizontal mining, as shown in Fig.2. 


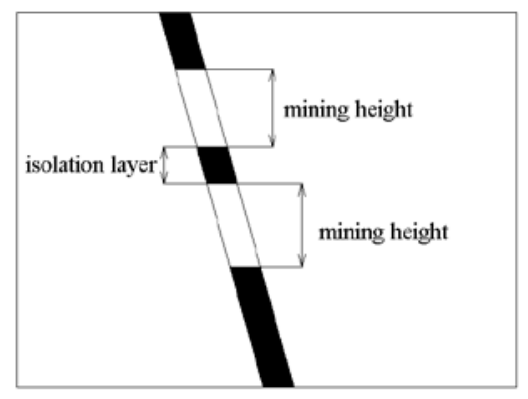

Fig.2 Map of mining height and isolation layer

In order to study the influence of the mining height to the fault activation and the thickness of the isolation layer to the fault activation. Arrange monitoring points in two walls of the fault every $50 \mathrm{~m}$ in the level $-100 \sim-400 \mathrm{~m}$, as shown in Fig.1 andTable 2. The mining height is $35 \mathrm{~m}$ and the thickness of the isolation layer is $5 \mathrm{~m}$ is the initial scheme, and monitor thedisplacement differential of the upper wall and the footwall in different monitoring points. Adjust the mining height and the isolation layer to the fault respectively, to study the fault activation condition in different schemes. The scheme design as shown in Table 3.

Table 2Monitoring location

\begin{tabular}{cccc}
\hline Monitoring point & Level/m & Monitoring point & Level $/ \mathrm{m}$ \\
\hline 1 & -100 & 5 & -300 \\
2 & -150 & 6 & -350 \\
3 & -200 & 7 & -400 \\
4 & -250 & - & - \\
\hline
\end{tabular}

Table 3 Simulation scheme

\begin{tabular}{ccc}
\hline Modeling scheme & Mining height/m & Thickness of the isolation layer $/ \mathrm{m}$ \\
\hline Scheme1 & 35 & 5 \\
Scheme2 & 35 & 6 \\
Scheme3 & 30 & 5 \\
\hline
\end{tabular}

\section{Simulation Results and Analysis}

According to the actual situation of the coal seam mining in the study area, we simulated the production process of the coal seam in the level of $-200 \mathrm{~m}$ to $-700 \mathrm{~m}$, and monitored the displacement differential of the upper wall and the footwall in different levels. The activation condition of the fault was judged by calculating thedisplacement differential of two walls of the fault.

Scheme 1.In the process of coal seam mining, the change of the displacement differential of the upper wall and the footwall with the mining depth are shown in Fig.3. In shallow mining in the study arear, the horizontal displacement differential and the vertical displacement differential of the upper wall and the footwall is very small, and there is no obvious change. When the mining depth is $-560 \mathrm{~m}$, the displacement differential of two walls of the fault in different monitoring points increased at the same time, the tensile failure and the shear failure occurred in the fault zone, the fault start to active. When the mining depth reaches $-700 \mathrm{~m}$, the displacement differential of the upper wall and the footwall in the monitoring points reach the maximum values. After the coal seam mining, the horizontal displacement differential and the vertical displacement differential of 
the upper wall and the footwall both appeared in the -300 m level, and the horizontal displacement differential is $32.1 \mathrm{~mm}$, the vertical displacement differential is $5.2 \mathrm{~mm}$.

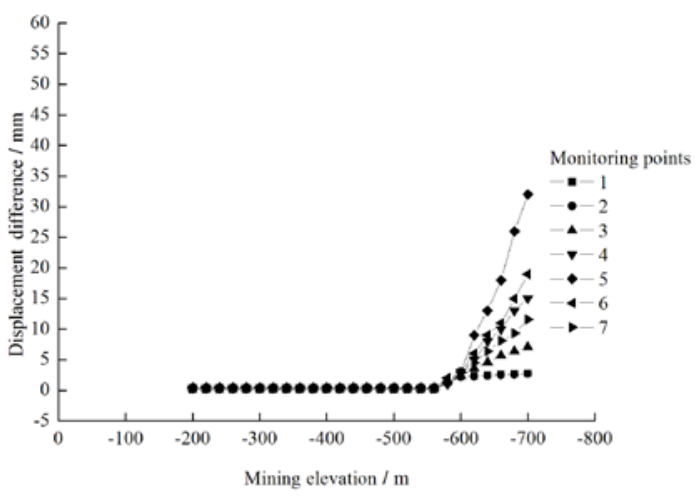

(a) Horizontal direction

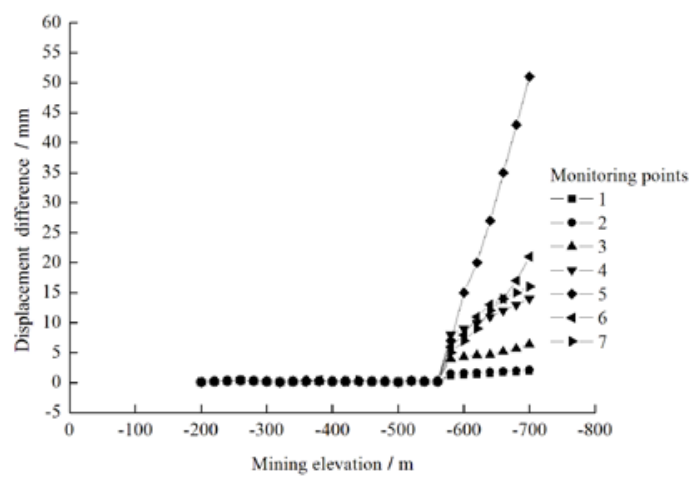

(b) Vertical direction

Fig.3Displacement differential between the upper wall and the footwall

Scheme 2.When the mining height is $35 \mathrm{~m}$ and the thickness of the isolation layer is $10 \mathrm{~m}$, the change of the displacement differential of the upper wall and the footwall with the mining depth are shown in Fig.4. When the mining depth is $-600 \mathrm{~m}$, the displacement differential of the upper wall and the footwall start to significantly increase with the mining depth. When the mining depth reaches $-700 \mathrm{~m}$, the displacement differential of the upper wall and the footwallin the monitoring points reach the maximum values. After the coal seam mining, the horizontal displacement differential and the vertical displacement differential of the upper wall and the footwall both appeared in the $-300 \mathrm{~m}$ level, and the horizontal displacement differential is $25.6 \mathrm{~mm}$, the vertical displacement differential is $30.1 \mathrm{~mm}$. The fault activation degree in the scheme 2 is weaker than that in scheme 1.

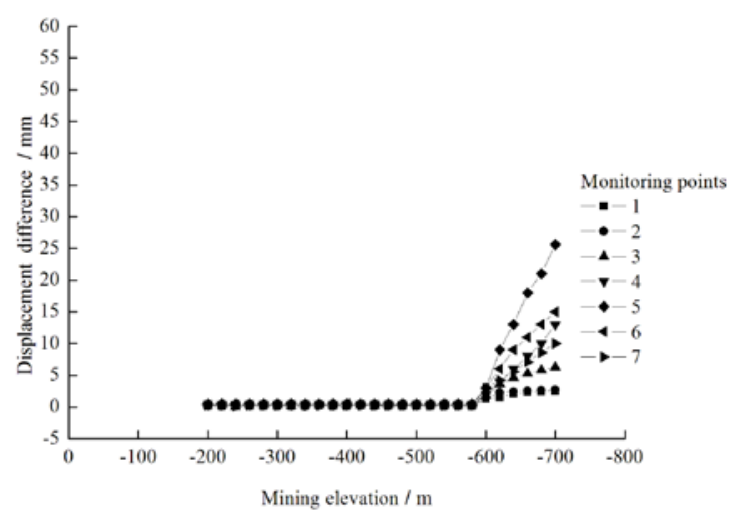

(a) Horizontal direction

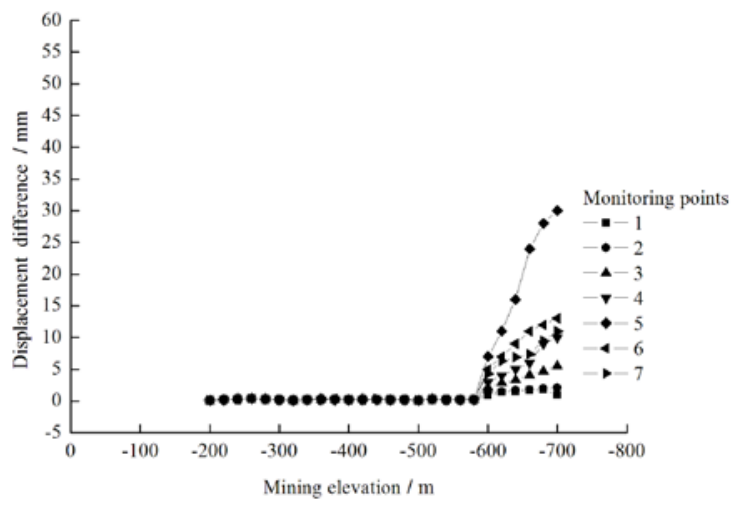

(b) Vertical direction

Fig.4 Displacement differential between the upper wall and the footwall after increasing the height of the partition coal pillars

Scheme 3. When the mining height is $30 \mathrm{~m}$ and the thickness of the isolation layer is $5 \mathrm{~m}$, the change of the displacement differential of the upper wall and the footwall with the mining depth are shown in Fig.5. When the mining depth is $-600 \mathrm{~m}$, the fault start to active. After the coal seam mining, the horizontal displacement differential and the vertical displacement differential of the upper wall and the footwall both appeared in the $-300 \mathrm{~m}$ level, and the horizontal displacement differential is $6.3 \mathrm{~mm}$, the vertical displacement differential is $12.2 \mathrm{~mm}$. The fault activation degree 
in the scheme 3 is weakest of the three schemes, therefore the decrease of the mining height can effectively reduce the activation of the fault.

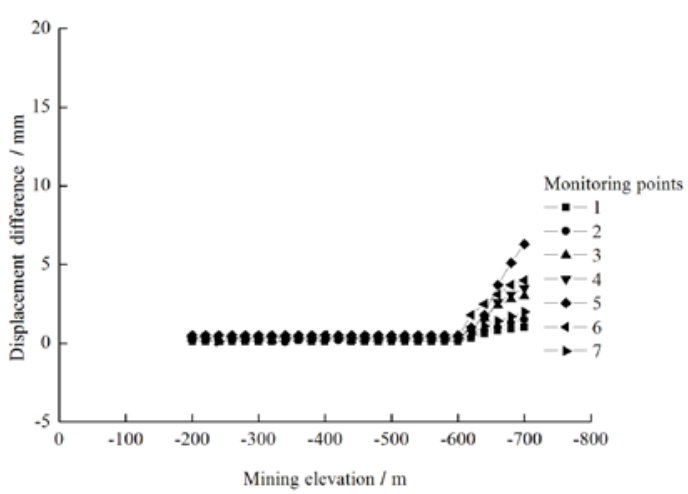

(a) Horizontal direction

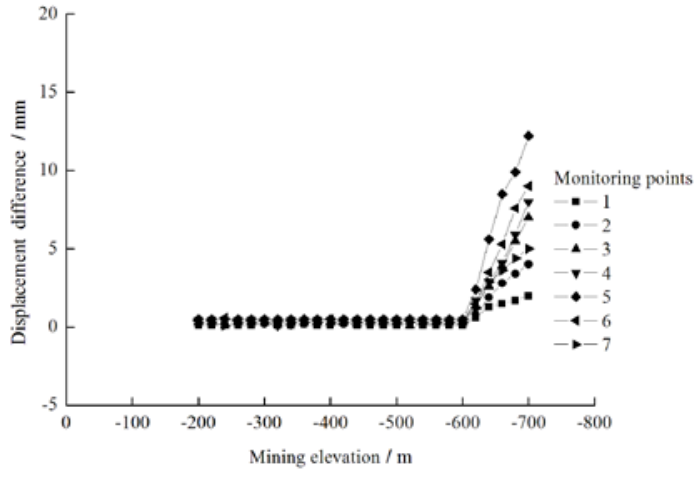

(b) Vertical direction

Fig.5 Displacement differential between the upper wall and the footwall after decreasing the height of the working face

According to the result of three kinds of simulation schemes, there is a range of mining depth in the mining steep coal seam. When the mining depth reaches this range, the fault in coal seam roof start to active. In the study area, when the mining depth reaches $-570 \mathrm{~m}$, the fault in coal seam roof start to active.

Table 4 The regression relationship between the displacement differential (horizontal and vertical) and the mining elevation in monitoring point 5 after fault activation

\begin{tabular}{ccc}
\hline Modeling scheme & The regression relation of $\mathrm{y}_{1}$ and $\mathrm{x}$ & The regression relation of $\mathrm{y}_{2}$ andx \\
\hline Scheme 1 & $y_{1}=(-0.2339 x-134.53) / 100$ & $y_{2}=(-0.3587 x-201.2) / 1000$ \\
Scheme 2 & $y_{1}=(-0.22 x-128.07) / 1000$ & $y_{2}=(-0.2486 x-142.24) / 1000$ \\
Scheme 3 & $y_{1}=(-0.0695 x-42.29) / 1000$ & $y_{2}=(-0.1195 x-71.15) / 1000$ \\
\hline
\end{tabular}

Note: $y_{1}$ is horizontal displacement; $y_{2}$ is vertical displacement; $x$ ismining elevation.

It can be seen from the Table 4, after the start of the activation of the fault, there are linear relationships between the displacement difference in horizontal direction and the mining level, and between the displacement difference in vertical direction and the mining level. The absolute value of regression coefficient in scheme 3 is the minimum in the three schemes, we can come to the conclusion that the decrease of the mining height can reduce the displacement differential of the upper wall and the footwall, and can also reduce the influence of the mining depth to fault activation.

\section{Conclusions}

(1) When mining the shallow coal seam in three kinds of simulation scenario, the displacement differential of the upper wall and the footwallin different levels is very small in both horizontal direction and vertical direction, and the change is not obvious, there is little affected by coal seam mining in the fault.

(2) According to the simulation results, the activation degree of the fault increased by the increase of the mining level, the maximum displacement differential of the upper wall and the footwallappeared in the monitoring point 5 in the level of $-300 \mathrm{~m}$.

(3) Increase the thickness of the isolation layer and decrease the mining height can decrease the displacement differential of the upper wall and the footwall. 
(4) The regression equations of the translocation of the upper wall and the footwall in the monitoring point 5 of the three schemes were established, through the analysis of the regression equations, we can come to the conclusion that the decrease of the mining height can reduce the displacement differential of the upper wall and the footwall, and can also reduce the influence of the mining depth to fault activation.

\section{Acknowledgments}

This study was financially supported by the Fundamental Research Funds for the Central Universities (2009QD03),Natural Science Foundation of Beijing Municipality (8122037) andNational Natural Science Foundation of China (41172213 and41272275), which we gratefully acknowledge.

\section{References}

[1]W.K. Pu, X.B. Mao,Research on effect of fault dip on fault activation and water inrush of coal floor, J. Chin. J.Rock Mech.Eng.28(2009) 386-394.

[2]Z.Q.Song, J. Hao, J.Q. Shang, Y.K. Dan, Study on water inrush from faults prevention and control theory [J]. J. Chin. Coal Soc. 38(2013)1511-1515.

[3]Q.F.Li, W.J. Wang, C.Q. Zhu, W.Q. Peng, Analysis of fault water-inrush mechanism based on the principle of water-resistant key strata, J. J.Min.Saf.Eng.26(2009)87-90.

[4]Z.H.Chen, Z.P. Hu, H. Li, Q.F. Chen, Fracture mechanical model and criteria of insidious fault water inrush in coal mines, J. J.Univ.MinTechnol.40(2001)673-677.

[5]S.N.Dong, W.Y. Hu, Basic characteristics and main controlling factors of coal mine water hazard in China, J. Coal Geol.Explor.35(2007)34-38.

[6]Y. Liu, Y.P. Wu, Y.S. Wang, The study of the width of waterproof pillar in upper wall, J. J. Xian Univ.Sci.Technol.30(2010)523-530.

[7]Z.P.Meng, S.P. Peng, H. Li, Influence of normal faults on the physical and mechanical propertiesof coal and the distribution of underground pressure, J. J. Chin. Coal Soc. 26(2004)561-566.

[8]W.Q.Peng, W.J. Wang, Q.F. Li, Reasonable width of water proof coal pillarunder the condition of different fault dip angles, J.Min.Saf.Eng.26(2009)179-182.

[9]Y.D. Jiang, T. Wang, T.X. Zhao, et al., Numerical simulation of fault activation pattern induced by coal extraction, J. J.Univ.Min.Technol.42(2013) 1-5.

[10]R. Pan, X.R. Meng, Z.N. Gao, Research and practice on floor fault water control in Huaibei mining area, J. Met. Mine.44 (2013) 148-152. 